\title{
The use and misuse of antibiotics in urology
}

\author{
Martin A. Koyle, MD, MSc
}

Department of Surgery, University of Toronto, Section of Pediatric Urology, The Hospital for Sick Children, Toronto, ON, Canada

Cite as: Can Urol Assoc J 2017;11 (1-2Suppl1):S12. http://dx.doi.org/10.5489/cuaj.4385

See related article on page S3.

$\mathrm{T}$ he use and misuse of antibiotics in all facets of urology - adult and pediatric - continues to foster controversy. One must always question, "Do we over-treat many (unnecessarily), with the hopes of protecting one?" Urinary tract infection (UTI) is the most common serious bacterial infection of infancy. Should we circumcise all males, knowing that 1:100-110 will have a UTI prevented?

Antenatal hydronephrosis (AHN) is a relatively new finding for our specialty, having become commonplace only in the last three decades with the popularity and availability of routine maternal-fetal ultrasound. AHN represents a spectrum, as does the propensity to developing a UTI and any sequelae from it. We know that most cases of AHN are lowgrade and tend to be transient. If we "over-investigate" all comers with AHN with a voiding cystourethrogram (VCUG), approximately $15 \%$ will have vesicoureteral reflux (VUR), again usually low-grade. Must we look and must we treat them too? As Maslow said, "I suppose it is tempting, if the only tool you have is a hammer, to treat everything as if it were a nail." ${ }^{1}$

By this "golden hammer," one tends to over-rely on a tool (investigational or therapeutic) that one is familiar with. In pediatric urology, historically we focused on images being equated with potential pathology and de facto, we (over) investigate and tend to (over) treat. The analysis above alludes to the fact that randomized, controlled trials are lacking and, at best, we are limited to comparative observational studies and subsequent lukewarm recommendations and guidelines developed based primarily on expert opinion and reliance on the "golden hammer," not evidence.

We look forward to the upcoming 2017 Canadian Urological Association (CUA) guidelines regarding AHN, particularly to see the changes in comparison to those previously published by Psooy in 2009. ${ }^{2}$

Competing interests: Dr. Koyle has been an advisor for Duchesnay.

This paper has been peer-reviewed.

\section{References}

1. Maslow AH (1966). The psychology of science: A reconnaissance. New York: Harper \& Row

2. Psooy K. Canadian Urological Association guidelines on antenatal hydronephrosis. Can Urol Assoc J 2009;1:69-72.

Correspondence: Dr. Martin A. Koyle, Department of Surgery, University of Toronto, Section of Pediatric Urology, The Hospital for Sick Children, Toronto, ON, Canada; martin.koyle@sickkids.ca 